\title{
On the Choice of the Optimal Temporal Control in Renewable Resource Management ${ }^{1}$
}

by

\author{
Amitrajeet A. Batabyal $^{2}$
}

and

\section{Hamid Beladi ${ }^{3}$}

We thank George Christakos and two anonymous referees for their comments on a previous version of this paper. Batabyal acknowledges financial support from the Gosnell endowment at RIT. The usual disclaimer applies.

2

Department of Economics, Rochester Institute of Technology, 92 Lomb Memorial Drive, Rochester, NY 14623-5604, USA. Internet aabgsh@ rit.edu

Department of Economics and Finance, University of Dayton, 300 College Park, Dayton, OH 45469-2251, USA. Internet beladi@udayton.edu 


\title{
On the Choice of the Optimal Temporal Control in Renewable Resource Management
}

\begin{abstract}
This paperaddresses the following hithertounstudied question in renewable resource management:

How should a resource manager set the temporal control optimally for renewable resources such as rangelands and fisheries that are managed with spatial and temporal controls? We use a dynamic and stochastic framework to first derive the resource manager's long run average net cost function. We then demonstrate how the temporal control can be chosen to minimize this objective function.
\end{abstract}

Keywords: Optimal Management, Renewable Resource, Spatial Control, Temporal Control 


\section{Introduction}

Spatial and temporal controls have been used to regulate the activities of a broad range of productive units in Europe and in North America (Kay and Morris (1987), Krueger (1996)). Even so, their use has been particularly widespread in the realm of renewable resource management. Weninger and Strand (1998) note that recreational and commercial hunters for most game are subject to seasonal restrictions. As well, such hunters are generally obliged to hunt during daylight hours. In addition to this, in almost every state in the USA, sport fishing seasons exist for a whole host of fish species. Commercial fisheries in Canada, the USA, and in western Europe are subject to a variety of spatial and temporal controls. ${ }^{4}$ As observed by Young (1981), fisheries in the US Pacific Northwest are routinely regulated with season length restrictions (a temporal control) and with area restrictions (a spatial control). Hartwick and Olewiler (1998, p. 156) have pointed out that on the US eastern seaboard, the Atlantic surf clam fishery has been regulated by controlling the days per week and the hours per day that fishing vessels can harvest (temporal controls) and by restricting harvests in areas where young clams reside (a spatial control). In what is now called short duration grazing, ${ }^{5}$ rangelands are managed by first dividing the land (or cell) under consideration into a number of paddocks and then by controlling both the length of time during which animals graze a paddock and by controlling the area of this paddock (Holechek et al., 2001, pp.

4

For a more detailed corroboration of this claim, see Young (1981), Karpoff (1987), Matulich et al. (1996), Hartwick and Olewiler (1998, pp. 152-175), and Weninger and Strand (1998).

5

Short duration grazing is also known as time controlled grazing and as cell grazing. In addition to short duration grazing, grazing systems such as the Merrill three herd and four pasture system and rest rotation grazing also have spatial and temporal control aspects to them. For more on this and related issues, see Batabyal (2001a, 2001b), Batabyal et al. (2001a, 2001b, 2001c), Batabyal and Yoo (2001), and Holechek et al. (2001, p. 269). 
269-277). Indeed, for rangelands managed with short duration grazing, it has been said that "a wellmanaged cell permits stocking rates to be increased substantially...compared to...other grazing systems" (Holechek et al., 2001, p. 271). This discussion tells us that as far as the management of renewable resources such as fisheries and rangelands is concerned, the use of spatial and temporal controls is standard. Nevertheless, to fix ideas, in the rest of this paper we shall focus on rangelands as our prototypical renewable resource. ${ }^{6}$

Consider the following two managementregimes under uncertainty: In the first regime, the resource manager uses one spatial and one temporal control. In the second regime, the resource manager uses either two spatial or two temporal controls. Is there any difference between these two management regimes? To see that the answer is yes note the following two things: First, the choice of spatial and temporal controls is typically a sequential process. Initially, the spatial control is chosen and then a temporal control is applied to the space under consideration. Second, spatial and temporal controls affect different dimensions of the management problem. A spatial control constrains resource use to a particular part of the relevant space (part of a fishery or a part of a cell). In contrast, a temporal control restricts resource use to a particular time period. The upshot of these two things is that, in general, two spatial (or temporal) controls will not have the same impact on resource use as one spatial and one temporal control.

Even though spatial and temporal controls have been and are used frequently in renewable resource management, we still know very little about the properties of optimal temporal controls for resources such as rangelands that are managed with spatial and temporal controls. Recently, Batabyal and Beladi (2001)

6

However, we stress that our analysis applies equally well to fisheries. 
and $\mathrm{Xu}$ and Batabyal (2001) have studied renewable resource management with temporal controls in a stochastic setting. Although these papers have shed valuable light on the properties of temporal controls in a stochastic setting, they have not analyzed the specifics of temporal controls for resources that are managed with spatial and temporal controls. Recently, Batabyal and Godfrey (2001) have analyzed a Markov chain theoretic model of range management. Although this last paper does provide some commentary on the spatial and the temporal control aspects of range management, it does not analyze the optimization problem concerning the choice of the optimal temporal control for a rangeland that is managed with spatial and temporal controls.

Given this state of affairs, the objective of this paper is to shed light on the following hitherto unstudied question in renewable resource management: How should a resource manager set the temporal control optimally for a rangeland that is managed with spatial and temporal controls? We use a dynamic and stochastic framework to first derive the rangeland resource manager's long run average net cost function. We then show how the temporal control can be chosen to minimize this objective function. The rest of this paper is organized as follows: Section 2 uses a dynamic and stochastic framework to derive the range manager's long run average net cost function. Next, this section shows how our manager can choose the temporal control to minimize this objective function. Section 3 concludes and offers suggestions for future research.

\section{Choosing the Temporal Control Optimally}

\subsection{Preliminaries}

In keeping with standard practice in short duration grazing (see Holechek et al., 2001, pp. 269270), suppose that the dynamic and stochastic rangeland or cell under study has been divided into a number 
of fenced paddocks of equal grazing capacity. A natural question now is the following: How many paddocks should the rangeland or cell be divided into? Although this question is addressed briefly in section 3, for the most part, we suppose that this issue has already been resolved. Given the stocking rate versus time controversy in the range management literature (see Savory and Butterfield (1998), Holechek et al. (2000), and Batabyal et al. (2001a, 2001b, 2001c)), our objective in this paper is to focus on the determination of the optimal temporal control. This is consistent with the view that overgrazing bears "little relationship to the number of animals but rather to the time plants [are] exposed to the animals" (Savory and Butterfield, 1998, p. 46, emphasis in original).

In short duration grazing, the paddocks_-into which the rangeland or cell has been divided — constitute the spatial control variable for our range manager. Put differently, during the relevant grazing season, one salient task performed by the range manager involves moving his herd of animals from one paddock to the next, in sequential fashion. Because these fenced paddocks are generally of equal grazing capacity (see Holechek et al., 2001, p. 269), the key question now concerns the determination of the manager's temporal control. How long should his herd of animals stay in a particular paddock before it is moved to the next paddock? This is a question of great importance for practical range management. Indeed, the success of short duration grazing depends in large part on choosing this temporal control variable optimally. Yet, to the best of our knowledge, there are no previous theoretical studies of this question. This lack of research has prevented one from "drawing very many definite conclusions about the effectiveness of various short-duration grazing strategies" (Holechek et al., 2001, p. 270). Given this state of affairs, we now use a dynamic and stochastic framework to derive our range manager's long run average net cost function. We then show that the optimal temporal control effectively minimizes this long run 
objective function.

\subsection{The theoretical framework}

Without loss of generality, consider an arbitrary paddock of the rangeland under study. To keep the problem interesting, we suppose that forage quality in this paddock is a random variable. To be consistent with units (also see footnote 8 ), suppose that the one-to-one and strictly monotone function $f(\cdot)$ maps the forage quality of a paddock to its "effective lifetime." The forage quality of an ungrazed paddock is a function of environmental factors only. ${ }^{7}$ In other words, such a paddock has the highest effective lifetime. As this paddock is grazed for progressively longer periods of time, its forage quality and hence its effective lifetime declines. Because forage quality is a random variable and because effective lifetime is a one-to-one and strictly monotonic transformation of forage quality, effective lifetime itself is a random variable. Let us denote the distribution and the density functions of effective lifetime by $G(\cdot)$ and $g(\cdot)$, respectively. In what follows, we shall not refer to the forage quality of a paddock; instead we shall speak of its effective lifetime. However, the reader should note that any specific value of effective lifetime refers unambiguously to a unique level of forage quality. Further, like all lifetimes, effective lifetime is measured in time units and it is defined over the non-negative real numbers.

Our range manager will terminate grazing in this particular paddock and move his herd of animals to the next paddock either when $T$ time periods have elapsed, or when a stochastic and adverse environmental event cuts down the effective lifetime of this paddock. When such an event occurs, from the

7

By "environmental factors," we mean things like droughts, unusually low soil moisture, and the presence of poisonous plants. 
standpoint of additional grazing, there is a breakdown of this paddock. ${ }^{8}$ Examples of such environmental events include unusually high rainfall in an arid paddock that results in significant topsoil loss, a fire that kills plants on the paddock, the appearance of blood sucking insects that stress cattle on the paddock, and the discovery of toxic agents such as alkaloids in paddock plants.

The completion of grazing in a particular paddock and the concomitant movement of the herd of animals to the next paddock results in benefits and costs to our manager. The benefits stem from things like animal weight gain and the costs arise from activities such as fencing. Let us denote the net cost to our manager from the completion of grazing on a paddock after $T$ time periods (one grazing cycle) by $c(p)$. If grazing on a paddock has to be terminated because of the occurrence of an adverse environmental event (a breakdown), then we suppose that in addition to $c(p)$, our manager incurs a net cost of $c(e)$. This additional net cost accounts for the fact that when an adverse environmental event occurs, additional expenditure will typically be incurred by our manager on things such as the repair of extant fences and the possible replacement of dead and/or diseased animals. Finally, consistent with reality, we suppose that even after $T$ time periods, from the manager's perspective, a paddock still has some residual grazing value. We denote this value by the function $b(T) .{ }^{9}$ Our task now is to determine the range manager's long run average net cost function.

To compute this cost function, we shall use renewal theory and specifically the renewal-reward

8

The reason for speaking in terms of the effective lifetime - and not the forage quality — of a paddock should now be clear. In what follows, we wish to compare $T$ (measured in time units) with another relevant random variable that is also measured in time units. This comparative exercise cannot be undertaken by comparing $T$ with forage quality directly.

9

If the paddock under study has no residual grazing value at time $T$ then the value of $b(T)$ is identically equal to zero. The reader should note that our analysis in the rest of this paper does go through in the case where $b(T) \equiv 0$. 
theorem. ${ }^{10}$ To apply this theorem to our context, it will be necessary to first compute the expected net cost per grazing cycle. To this end, define $i$ to be an indicator variable, where

$$
i=\left\{\begin{array}{c}
1 \text { if } L<T \\
0 \text { if } L \geq T,
\end{array}\right.
$$

and $L$ is the effective lifetime of the paddock. With this definition in place we can see that the net cost incurred by our manager per grazing cycle on a paddock, i.e., when grazing is terminated either because of the adverse environmental event or because $T$ time periods have elapsed, is

$$
\text { Cost Per Grazing Cycle }=c(p)+c(e) i-b(T)\{1-i\} \text {. }
$$

Now taking the expectation of both sides of equation (2), we get

$$
E[\text { Cost Per Grazing Cycle }]=c(p)+c(e) G(T)-b(T)\{1-G(T)\}
$$

The next step in our derivation of the manager's average net cost function involves computing the expected amount of time it takes to complete a grazing cycle. To compute this expectation, we shall use the notion of a conditional expectation. Using this notion, we get of these subjects, see Kulkarni (1995, pp. 452-459), Taylor and Karlin (1998, pp. 447-457), and Ross (2000, pp. 377-386). 
where $l$ is a realization of the effective lifetime random variable $L$. Using the properties of the conditional expectation, the right hand side (RHS) of equation (4) can be simplified further. This simplification gives

$$
\text { E[Time Until Completion Of Grazing Cycle }]=\int_{0}^{T} \lg (l) d l+T\{1-G(T)\} \text {. }
$$

We are now in a position to state our manager's long run average net cost function. By the renewalreward theorem (see Ross (2000, p. 378)), this function is given by dividing equation (3) by equation (5). Performing this division, we get

$$
\text { Long Run Average Net Cost }=\frac{c(p)+c(e) G(T)-b(T)\{1-G(T)\}}{\int_{0}^{T} \lg (l) d l+T\{1-G(T)\}} .
$$

Equation (6) describes our range manager's objective function. The reader should note two things. First, the stochastic framework of this paper does affect the derivation of our manager's objective function. This is because the manager's long run average net cost depends on the distribution function of the "effective lifetime" random variable. Second, this manager's goal is to choose $T$, the length of the grazing cycle on a paddock, to minimize the long run average net cost of management operations. In the general case, irrespective of the specific functional forms for the $b(\cdot)$ and the $G(\cdot)$ functions, our manager will always choose $T$ to minimize the RHS of equation (6). However, in this general case, the underlying minimization problem is unwieldy and it is not possible to obtain an explicit solution for the optimal temporal control. 
Consequently, we now illustrate the approach of this paper by using specific numerical values, a functional form for the residual grazing value function, and by supposing that effective lifetime (in days) is uniformly ${ }^{11}$ distributed over $(2,8)$.

\subsection{An example}

In hundreds of dollars, suppose that $c(p)=\$ 4, c(e)=\$ 1$, and that the residual grazing value function $b(T)=4-(T / 2)$. Now, using this information and the assumption that $L \sim U(2,8)$, equation (6) can be simplified. This simplification yields Long Run Average Net Cost $=\left(18 T-20-T^{2}\right) /\left(16 T-4-T^{2}\right)$. As such, our manager's problem is to solve

$$
\min _{\{T\}} \frac{18 T-20-T^{2}}{16 T-4-T^{2}}
$$

Using calculus, it is easy to see that this minimand is increasing in $T$ over the interval $(2,8)$. Hence, the optimal value of $T, T^{*}=2$.

In this example, our manager's optimal course of action is as follows: Graze a paddock for two days, then terminate grazing on this paddock and move the herd of animals to the next paddock, and keep proceeding in this fashion. A manager who follows this decision rule will accomplish two goals simultaneously. First, he will ensure that range operations are conducted at the lowest average net cost. Second, because our manager's focus is on the long run (see equation (6)), by choosing the temporal control in the manner just described, our manager will also ensure that the rangeland under study is used

11

Alternately, one could analyze the case in which effective lifetime is exponentially distributed. 
sustainably. In other words, this rangeland will be able to provide society with a flow of consumptive and non-consumptive services on a sustained basis.

\section{Conclusions}

We addressed an issue in this paper that, to the best our knowledge, has not been addressed previously in the literature on the management of renewable resources. Specifically, we answered the following question: How should a resource manager set the temporal control optimally for a rangeland that is managed with spatial and temporal controls? To answer this question, we used a dynamic and stochastic framework to derive the rangeland manager's long run average net cost function. With the aid of a numerical example, we then showed how the temporal control can be chosen optimally to minimize this objective function.

Like rangelands, many fisheries — also see footnote 6-are divided into areas (controlled spatially) and these areas are then subject to season length restrictions (temporal controls). Consequently, the question of determining the temporal control optimally is germane in the realm of fisheries management as

well. As such, it is important to note that the applicability of this paper's analysis extends beyond rangelands.

The analysis contained in this paper can be augmented in a number of directions. In what follows, we suggest two possible extensions of this paper's research. First, recall that in section 2.1 we assumed that the question of the number of paddocks that a rangeland (cell) should be divided into has already been resolved. One way to extend the research of this paper would be to analyze a two-stage model in which the spatial control is chosen in the first stage and then the temporal control is selected in the second stage. Second, it would be helpful to determine which distribution functions are most useful in modeling the 
"effective lifetime" random variable. Studies of renewable resource management that incorporate these aspects of the problem into the analysis will provide additional insights into the behavior of resources that are managed with spatial and temporal controls. 


\section{References}

Batabyal, A.A. 2001a. Some Theoretical Aspects of Short Duration Grazing, Unpublished Manuscript, Rochester Institute of Technology.

Batabyal, A.A. 2001b. On the Optimal Number of Paddocks in Short Duration Grazing. Forthcoming, Journal of Economic Research.

Batabyal, A.A., and Beladi, H. 2001. Time Restrictions in Natural Resource Management: A Dynamic and Stochastic Analysis, Unpublished Manuscript, Rochester Institute of Technology.

Batabyal, A.A., Biswas, B., and Godfrey, E.B. 2001a. A Dynamic and Stochastic Perspective on the Role of Time in Range Management, Unpublished Manuscript, Rochester Institute of Technology.

Batabyal, A.A., Biswas, B., and Godfrey, E.B. 2001b. On the Choice Between the Stocking Rate and Time in Range Management. Forthcoming, Environmental and Resource Economics.

Batabyal, A.A., Biswas, B., and Godfrey, E.B. 2001c. The Stocking Rate Versus Time in Range Management: A Review of Recent Theoretical Developments, Applied Economics Letters, 8, 555-559.

Batabyal, A.A., and Godfrey, E.B. 2001. Rangeland Management Under Uncertainty: A Conceptual Approach. Forthcoming, Journal of Range Management.

Batabyal, A.A., and Yoo, S.J. 2001. The Steady State Distribution of Animals in Short Duration Grazing. Forthcoming, Applied Economics Letters.

Hartwick, J.M., and Olewiler, N.D. 1998. The Economics of Natural Resource Use, $2^{\text {nd }}$ edition. 
Addison-Wesley, Reading, Massachusetts.

Holechek, J.L., Gomes, H., Molinar, R., Galt, D., and Valdez, R. 2000. Short-Duration Grazing: The Facts in 1999, Rangelands, 22, 18-23.

Holechek, J.L., Pieper, R.D., and Herbel, C.H. 2001. Range Management, $4^{\text {th }}$ edition. Prentice-Hall, Upper Saddle River, New Jersey.

Karpoff, J.M. 1987. Suboptimal Controls in Common Resource Management: The Case of the Fishery, Journal of Political Economy, 95, 179-194.

Kay, J.A., and Morris, C.N. 1987. The Economic Efficiency of Sunday Trading Restrictions, Journal of Industrial Economics, 36, 113-130.

Krueger, A.B. 1996. Observations on International Labor Standards and Trade, Working Paper \# 362, Princeton University, Princeton, New Jersey.

Kulkarni, V.G. 1995. Modeling and Analysis of Stochastic Systems. Chapman and Hall, London, United Kingdom.

Matulich, S.C., Mittelhammer, R.C., and Roberte, C. 1996. Toward a More Complete Model of Individual Transferable Fishing Quotas: Implications of Incorporating the Processing Sector, Journal of Environmental Economics and Management, 31, 112-128.

Ross, S.M. 2000. Introduction to Probability Models, $7^{\text {th }}$ edition. Harcourt Academic Press, San Diego, California.

Savory, A., and Butterfield, J. 1998. Holistic Management, $2^{\text {nd }}$ edition. Island Press, Washington, District of Columbia.

Taylor, H.M., and Karlin, S. 1998. An Introduction to Stochastic Modeling, $3^{\text {rd }}$ edition. Academic 
Press, San Diego, California.

Weninger, Q., and Strand, I.E. 1998. Regulating Production Time to Control Output: An Application to a Harvest Technology, Unpublished Manuscript, Utah State University.

Xu, Q., and Batabyal, A.A. 2001. A Theoretical Analysis of Season Length Restrictions in Fisheries Management, Unpublished Manuscript, Rochester Institute of Technology.

Young, O.R. 1981. Natural Resources and the State. University of California Press, Berkeley, California. 